\title{
Noninvasive Respiratory Support During Pediatric Ground Transport: Implementation of a Safe and Feasible Procedure
}

\author{
Nuria Millán MD, Carme Alejandre MD, Aina Martinez-Planas MD, Josep Caritg PhD MD, \\ Elisabeth Esteban PhD MD, and Martí Pons-Òdena PhD MD
}

\begin{abstract}
BACKGROUND: The purpose of this work was to determine the safety and feasibility of noninvasive support in children with acute respiratory failure (ARF) during interhospital ground transport. METHODS: This was a prospective, single-center observational clinical study in the pediatric transport unit of a tertiary-care pediatric hospital. We included all subjects with ARF transported from November 2010 to March 2013. A specific noninvasive support protocol was used for all cases. Transport ventilators used were the Crossvent $2+$ and Oxylog 3000; interfaces were an oronasal mask, nasopharyngeal tube, or nasal prongs. RESULTS: A total of 288 children diagnosed with ARF were transported. Fifty-four subjects (19\%) were transported with invasive ventilation, 50 with CPAP, 58 with NIV, and 126 (44\%) with oxygen cannula or nebulization. The median age was 3.4 months (interquartile range 1.2-17 months). ARF was mainly due to bronchiolitis (58\%), asthma $(15 \%)$, and pneumonia $(15 \%)$. Stabilization time, which is defined as the time between the arrival in the parking lot of the referring hospital and departure, was lower with noninvasive support than with invasive ventilation (median $48 \mathrm{~min}$ vs $83 \mathrm{~min}, P<.001$ ). Median transport time was $35 \mathrm{~min}$ (interquartile range 20-65). Noninvasive ventilation and oronasal interface use rose progressively during the study period $(P<.001$ for the NIV and $P<.036$ for the interface). One complication was observed: One subject required intubation during transport. Evolution of subjects transferred while receiving noninvasive support was recorded in the receptor hospitals: $21 \%$ of subjects were intubated, and $55 \%$ continued with NIV. CONCLUSIONS: NIV seems to be a safe and feasible technique during pediatric ground transport. Careful patient selection, adequate material, and a well-trained transport team are crucial to minimize risks to the patient. Key words: noninvasive ventilation; critically ill; transport; child; respiratory failure; high-flow nasal cannula. [Respir Care 2017;62(5):558-565. (c) 2017 Daedalus Enterprises]
\end{abstract}

\section{Introduction}

Acute respiratory failure (ARF) is a major cause of morbidity and mortality in pediatric patients and a common reason for transport to a tertiary health-care center. ${ }^{1}$

Drs Millán, Alejandre, Martinez-Planas, Caritg, and Esteban are affiliated with the Pediatric Transport Unit, and Drs Millán, Alejandre, Esteban, and Pons-Odena are affiliated with the Pediatric Intensive Care Unit (PICU), Hospital Sant Joan de Déu, Esplugues de Llobregat, Barcelona, Spain.

Dr Pons-Òdena has disclosed relationships with Maquet, Dräger, Fisher \& Paykel, Air Liquide, Philips, and ResMed. The other authors have disclosed no conflicts of interest.
The use of noninvasive support, including noninvasive ventilation (NIV), has been increasing in pediatric ICUs (PICUs) ${ }^{2,3}$ and has proven to be beneficial in bronchiolitis, pneumonia, neuromuscular diseases, hypoxemic and hypercapnic ARF, upper airway obstruction, and status asth-

\footnotetext{
Dr Millán presented a version of this work at the First International NIV Meeting, held September 11-13, 2013, in Barcelona, Spain.

Supplementary material related to this paper is available at http:// www.rcjournal.com.
}

Correspondence: Nuria Millán MD, Pg. Sant Joan de Déu, 2. 08950, Esplugues de Llobregat, Barcelona, Spain. E-mail: nmillan@hsjdbcn.org.

DOI: $10.4187 /$ respcare. 05253 
maticus. ${ }^{4-6}$ The randomized controlled trial by Yañez et $\mathrm{al}^{7}$ in children with common causes of ARF showed a $32 \%$ reduction in the PICU intubation rate in the NIV group compared with standard medical treatment. It is likely that earlier application of NIV could contribute to decreasing intubation rates, ${ }^{8}$ although this needs to be further demonstrated in pediatrics.

A few adult studies in the prehospital setting showed a reduction in the number of intubations and mortality in subjects with ARF who received early CPAP, especially in acute pulmonary edema. ${ }^{9-11}$ The benefit of NIV is also clear in COPD exacerbations. ${ }^{12,13}$ Nasal CPAP is an effective respiratory support for term and preterm infants and has been described in neonatal road transport as a safe procedure. ${ }^{14}$ Nevertheless, NIV use in the out-of-hospital setting has been poorly studied in children, with only small studies published..$^{15,16}$ These studies reported on neonates, infants, and children with ARF but also included some NIV-dependent patients with neurologic or pulmonary diseases. The use of both high-flow nasal cannula (HFNC) ${ }^{17}$ therapy and NIV during transport showed good results.

Noninvasive support during transport could allow the initiation of this therapy at least 1 or $2 \mathrm{~h}$ before PICU admission, depending on the distance. Early treatment may be crucial if we consider the importance of reducing work of breathing in ARF. ${ }^{18,19}$ NIV has been widely and successfully used in the PICU of our hospital since 1998. Later on, it has been progressively implemented in our transport unit since 2010. The first aim of this study was to show the safety of noninvasive support in children with ARF during interhospital ground transport. The second aim was to demonstrate the feasibility of this type of respiratory support in this setting.

\section{Methods}

\section{Study Design}

This was a single-center, prospective, observational study conducted from November 2010 to March 2013 in the transport unit of a tertiary-care pediatric hospital. We developed a protocol based on the previous experience of the PICU team, tested it in the first year of the study, and improved on it over the next 2 years (see the protocol in the supplementary materials at http://www.rcjournal.com).

All children with ARF referred for ground transport were included in our study except for those proceeding from a neonatal unit, which was the only exclusion criterion, because the etiology of ARF in this group is usually distinct from the PICU population. The study was approved by the ethics board of Hospital Sant Joan de Déu, who waived the need for informed consent from the parents or legal guardians because noninvasive support is a standard treatment in our center.

\section{QUICK LOOK}

\section{Current knowledge}

Acute respiratory failure is a major cause of morbidity and mortality in pediatric patients and a common reason for transport to a tertiary health-care center. In pediatrics, the use of noninvasive support has been increasing. It is likely that earlier application of noninvasive support could contribute to decreasing intubation rates. Nevertheless, the use of noninvasive support in the out-of-hospital setting has been poorly studied in children.

\section{What this paper contributes to our knowledge}

Noninvasive support was feasible during pediatric ground transport in subjects with acute respiratory failure. It allowed the approach of this support to referring hospitals and an earlier application. Noninvasive support improved subjects' condition during transfer to pediatric ICUs. No significant adverse effects were documented.

\section{Pediatric Retrieval System Characteristics}

The pediatric transport unit is the provider of emergency medical services for Catalonia, a Spanish region of almost 7 million people, with 2 mobile PICUs staffed by a fully dedicated, specialized pediatric intensive care transport team: a pediatrician, a nurse, and an emergency medical technician, all trained in pediatric advanced life support and noninvasive respiratory support.

\section{Indications for Noninvasive Support}

NIV/CPAP was indicated when the patient had moderate/severe dyspnea or if apneas appeared. Some specific contraindications during transport were included to avoid complications during transport (see the supplementary material). NIV/CPAP was also excluded when the stabilization time was expected to be longer than the duration of the transport. NIV failure was defined as the need to remove the NIV initiated by our transport team, due to insufficient subject interfaces, lack of adequate trigger, or need for intubation due to disease progression.

\section{Implementation of NIV/CPAP}

Noninvasive support was provided by 2 different transport ventilators, the Oxylog 3000 (Dräger Medical, Lübeck, Germany) or the Crossvent 2+ (Bio-Med Devices, Guilford, Connecticut). 
CPAP values ranged between 5 and $10 \mathrm{~cm} \mathrm{H}_{2} \mathrm{O}$ pressure; NIV included maximum inspiratory positive airway pressure of $18 \mathrm{~cm} \mathrm{H}_{2} \mathrm{O}$ with expiratory positive airway pressure of $5-8 \mathrm{~cm} \mathrm{H}_{2} \mathrm{O}$.

Several interfaces were used. The mask was secured with head straps, and a hydrocolloid dressing was applied over the nasal bridge when necessary to prevent pressure sores.

Sedation was considered to facilitate the adaptation to respiratory support. We used sucrose in neonates and drugs, such as levomepromazine, ketamine plus midazolam, and propofol, depending on age and cause of ARF.

\section{Data Collection}

For each subject we collected: age; cause of ARF; severity of dyspnea, measured before treatment using the Wood-Downes score modified by Ferrés for asthma and the BROSJOD score for bronchiolitis (see supplementary materials) ${ }^{20-22}$; stabilization time (time required by the team from arrival in the parking lot to departure from the referring hospital); transport time (time spent from referring hospital departure to receptor hospital admission); transport ventilator used; respiratory treatment applied (oxygen, nebulization, CPAP, NIV, or invasive mechanical ventilation; type of interface; complications during transport; evolution in the receptor hospital; physiological variables (heart rate, breathing frequency, and $\mathrm{S}_{\mathrm{pO}_{2}} / \mathrm{F}_{\mathrm{IO}_{2}}$ ), measured prior to and at the end of the transport.

\section{Statistical Analysis}

Categorical variables were expressed as percentages and frequencies, and continuous variables were expressed as means and SD or medians and interquartile range, depending on the variable distribution. Quantitative continuous variables were compared among the groups using the unpaired Student $t$ test or the Mann-Whitney $U$ test accordingly. The Wilcoxon test was used to analyze paired variables. Statistical significance was set at $P<.05$. The statistical analysis was performed using SPSS 17 (SPSS, Chicago, Illinois).

\section{Results}

There were 1,317 interhospital pediatric transports performed by our transport team during the study, 288 due to ARF. Sex distribution was $62 \%$ males. The median age was 3.4 months (interquartile range 1.2-17 months).

ARF was mainly due to bronchiolitis (58\%), asthma $(15 \%)$, and pneumonia (15\%). Other less frequent causes were laryngitis and apneas. Forty-nine percent of the subjects had moderate dyspnea, and $40 \%$ had severe ARF according to the clinical scores (Table 1).
Fifty-four subjects (19\%) were transported with invasive mechanical ventilation and $126(44 \%)$ with oxygen cannula or nebulization. A total of 108 subjects were transported while receiving NIV/CPAP (37\%) (Table 2).

Figure 1 shows the flow chart with the stabilization measures applied by our retrieval team before the transport. During stabilization by our team in the referring hospital, NIV failed in 16 subjects: 6 due to lack of improvement, 6 due to poor tolerance to NIV, and 4 because interfaces were inappropriate in size. Six subjects had to be intubated before transport, with an average stabilization time of 109 min.

Stabilization time of subjects receiving noninvasive support in the referring hospital was $48 \mathrm{~min}$ versus $83 \mathrm{~min}$ in cases of conventional mechanical ventilation $(P<.001)$. Subjects transported with oxygen or nebulization had the lowest time of stabilization, with a median of $30 \mathrm{~min}$ $(P<.001)$. No significant differences were observed in stabilization time throughout the study. Transport time in the NIV/CPAP group ranged between 20 and $70 \mathrm{~min}$.

The use of oronasal interfaces and the Oxylog 3000 transport ventilator increased from $6 \%$ in both during period 1 to 40 and $42 \%$, respectively, in period 3 . NIV use rose progressively from 22 to $72 \%$ during the study $(P<.001)$ (Table 1$)$, with a median respiratory support of inspiratory positive airway pressure of $14 \mathrm{~cm} \mathrm{H}_{2} \mathrm{O}$ and expiratory positive airway pressure of $6 \mathrm{~cm} \mathrm{H}_{2} \mathrm{O}$.

The most common adverse event encountered during transport was intolerance to the NIV/CPAP interface, in 3 subjects $(3 \%)$. Only one subject of $108(1 \%)$ had to be intubated during transport due to a fast progression of the ARF. No other complication resulted from NIV/CPAP in our subjects. Sedation was needed in $26 \%$ of the NIV/CPAP cases. No secondary effects or associated complications were seen with the use of sedatives.

The severity of dyspnea was classified as severe in 114 subjects (40\%): $43 \%$ of them were transferred intubated, $39 \%$ receiving NIV/CPAP, and $18 \%$ receiving nebulization or oxygen. One hundred forty-two subjects (49\%) had moderate respiratory failure: only $3 \%$ required mechanical ventilation for the transport, $42 \%$ were receiving NIV, and $55 \%$ received nebulization or oxygen (Table 2 ).

Fifty-four subjects were transported with invasive mechanical ventilation: $33(61 \%)$ were intubated by physicians of the referring hospital, 11 (20\%) were intubated by our transport team upon arrival, and $10(19 \%)$ were intubated after HFNC or NIV was tried (Fig. 1). The evolution of the NIV/CPAP group in the different tertiary-care receptor hospitals was as follows: 59 subjects (55\% of this group) continued with this therapy, $23(21 \%)$ needed invasive mechanical ventilation (15 subjects during the first $12 \mathrm{~h}$ and only 4 subjects in the first $2 \mathrm{~h}$ of admission to the PICU). In 22 subjects (20\%), the hospital changed NIV/CPAP to HFNC or oxygen therapy (10 during the first $2 \mathrm{~h}$ ) (Fig. 2). 
Table 1. Comparison of the Study Periods

\begin{tabular}{|c|c|c|c|c|c|}
\hline Characteristics & $\begin{array}{l}\text { Period 1: } \\
\text { November } 10 \\
\text { to August } 11\end{array}$ & $\begin{array}{l}\text { Period 2: } \\
\text { September } 11 \\
\text { to June } 12\end{array}$ & $\begin{array}{l}\text { Period 3: } \\
\text { July } 12 \\
\text { to March } 13\end{array}$ & $\begin{array}{l}\text { Total or Overall } \\
\text { November } 10 \\
\text { to March } 13\end{array}$ & $P$ \\
\hline Subjects, $n$ & 66 & 98 & 124 & 288 & \\
\hline Male sex, $\%$ & 59 & 68 & 58 & 62 & .26 \\
\hline Age, median (IQR) months & $3.4(1.3-12.5)$ & $2.98(1.2-17)$ & $4.3(1.3-23)$ & $3.4(1.2-17)$ & .51 \\
\hline Cause of ARF, \% & & & & & .56 \\
\hline Bronchiolitis & 59 & 65 & 52 & 58 & \\
\hline Wheezing & 14 & 14 & 17 & 15 & \\
\hline Pneumonia & 12 & 12 & 17 & 15 & \\
\hline Severity, \% & & & & & .046 \\
\hline Mild & 17 & 11 & 8 & 11 & \\
\hline Moderate & 56 & 40 & 53 & 49 & \\
\hline Severe & 27 & 49 & 38 & 40 & \\
\hline Transport respiratory support, $\%$ & & & & & .032 \\
\hline $\mathrm{O}_{2} /$ neb & 61 & 41 & 37 & 44 & \\
\hline NIV/CPAP & 27 & 38 & 43 & 37 & \\
\hline Invasive ventilation & 12 & 21 & 20 & 19 & \\
\hline Stabilization time, median (IQR) min & $45(30-60)$ & $47(35-71)$ & $43(30-60)$ & $45(31-61)$ & .16 \\
\hline Transport time, median (IQR) min & $43(25-66)$ & $40(15-60.5)$ & $32.5(18-63.5)$ & $35(20-65)$ & .18 \\
\hline Ventilator, \% & & & & & .046 \\
\hline Home ventilator & 5 & 0 & 3 & 3 & \\
\hline Crossvent & 89 & 60 & 55 & 62 & \\
\hline Oxylog & 6 & 40 & 42 & 35 & \\
\hline Interfaces, \% & & & & & .036 \\
\hline Oronasal & 6 & 32 & 40 & 31 & \\
\hline Others & 94 & 68 & 60 & 69 & \\
\hline Respiratory support, \% & & & & & .001 \\
\hline CPAP & 78 & 57 & 28 & 46 & \\
\hline NIV & 22 & 43 & 72 & 54 & \\
\hline $\begin{array}{l}\mathrm{IQR}=\text { interquartile range } \\
\mathrm{ARF}=\text { acute respiratory failure } \\
\text { neb = nebulization } \\
\mathrm{NIV}=\text { noninvasive ventilation }\end{array}$ & & & & & \\
\hline
\end{tabular}

Table 2. Respiratory Support During Transport Depending on Severity of Respiratory Failure

\begin{tabular}{lcccr}
\hline \hline \multicolumn{1}{c}{ Respiratory Failure } & $\begin{array}{c}\text { Invasive } \\
\text { Ventilation }\end{array}$ & NIV/CPAP & $\mathrm{O}_{2} /$ neb & Total \\
\hline Mild ARF, $n(\%)$ & $0(0)$ & $5(16)$ & $27(84)$ & 32 \\
Moderate ARF, $n(\%)$ & $5(3)$ & $59(42)$ & $78(55)$ & 142 \\
Severe ARF, $n(\%)$ & $49(43)$ & $44(39)$ & $21(18)$ & 114 \\
Total, $n$ & 54 & 108 & 126 & 288 \\
& & & & \\
NIV $=$ noninvasive ventilation & & & & \\
neb $=$ nebulization & & & & \\
ARF $=$ acute respiratory failure & & & & \\
\hline
\end{tabular}

\section{Discussion}

As far as we know from a review of the literature, the present study is the largest prospective study of noninvasive support focused on ground transport in pediatric sub- jects. Only 2 pediatric studies reporting their experience using different types of respiratory support during transport were found. First, Baird et $\mathrm{al}^{16}$ reported successful interhospital ground transports of 25 children affected by a broad spectrum of disorders and transported with NIV. However, although there were no significant complications, $>25 \%$ of the transports required the use of advanced pediatric airway skills by the transport personnel (airway suctioning, bag-valve-mask ventilation, and cough-assist therapies). ${ }^{16}$ In our study, we only observed 3\% minor incidents, and only 1 subject had to be intubated during transport. It seems clear that a meticulous patient selection, avoiding those at high risk of failure, is crucial to avoid potential complications during transport, and, in fact, this is one of the main points of our protocol.

Second, Schlapbach et al ${ }^{17}$ observed a 2 -fold reduction in intubations performed by their transport team with the use of HFNC therapy. We were not able to show the same 


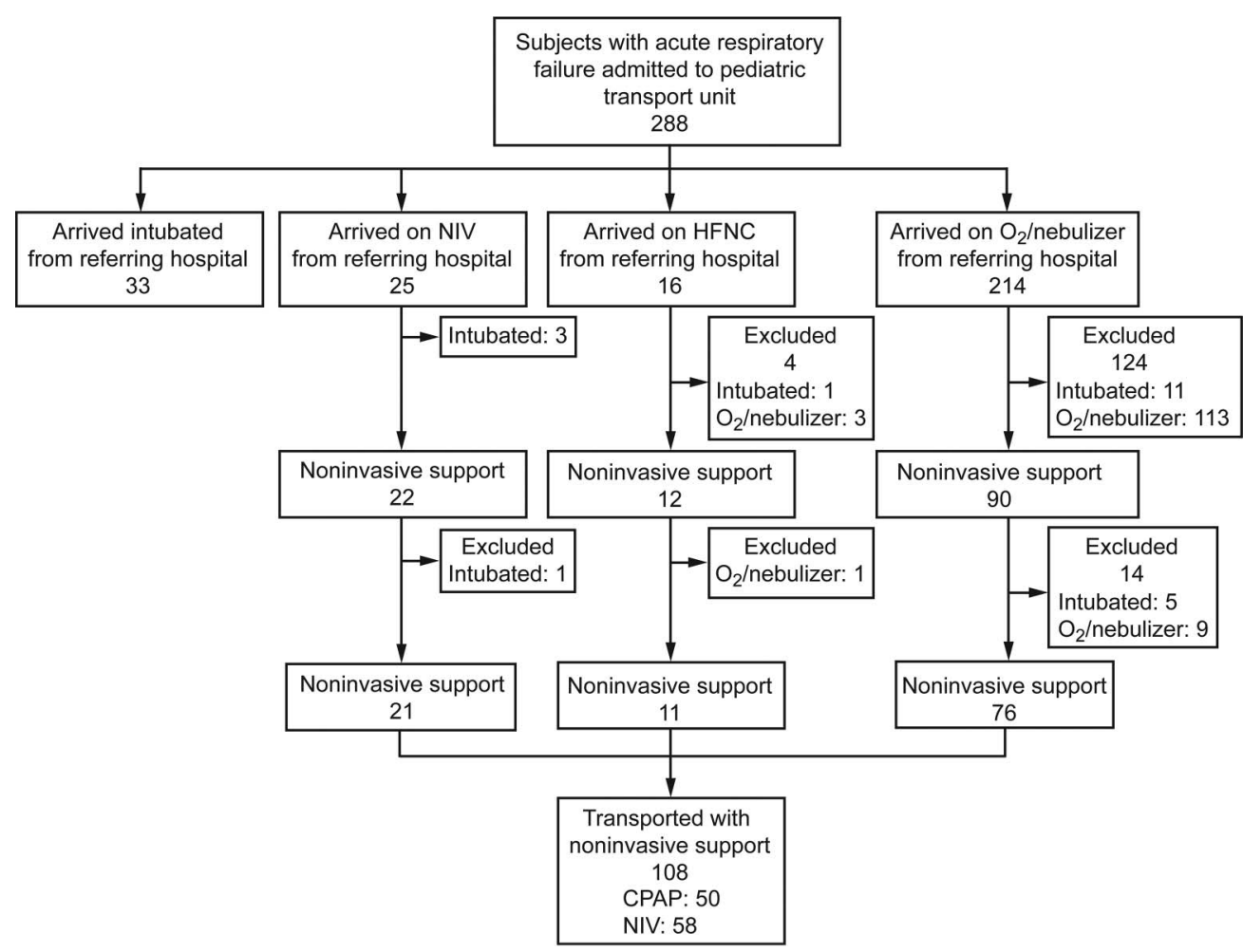

Fig. 1. Flow chart showing the stabilization measures applied by the retrieval team before transport. HFNC $=$ high-flow nasal cannula, NIV $=$ noninvasive ventilation.

positive results, but these 2 studies are not comparable: We included subjects with different types of ARF, age, etc, and our study was not designed for this aim; 44 of the 54 subjects who needed invasive mechanical ventilation were intubated for transport (33 by the referring hospital) without even a chance for an NIV/CPAP trial due to the severity of the ARF. This percentage did not diminish in any of the 3 periods of the study despite the increase in our use of noninvasive support. A possible explanation for this could be that stable and strict criteria for pretransfer intubation were maintained throughout the course of the study because patient safety during transport was our main concern.

In our study, bronchiolitis was the predominant condition requiring transport and NIV/CPAP therapy (65\%). Several studies confirmed the effectiveness of CPAP in bronchiolitis as a first step ${ }^{23,24}$ as well as HFNC therapy, ${ }^{25}$ with NIV rescue treatment to increase alveolar ventilation while reducing dyspnea and inspiratory effort. ${ }^{18}$ The PICU of Hospital Sant Joan de Déu showed a 63\% success rate when NIV was used with nasopharyngeal tubes for rescuing bronchiolitis patients failing while receiving CPAP. ${ }^{26}$

The use of NIV or CPAP in our study depended on the severity of the ARF (BROSJOD score >10) or lack of improvement while receiving CPAP. We used NIV in $43 \%$ of our bronchiolitis subjects. There is a scarcity of studies comparing CPAP versus NIV in bronchiolitis, with the use of CPAP ranging from 36 to $64 \% .^{27,28}$

In the subjects younger than 6 months, $46 \%$ were transported with a nasopharyngeal tube, and oronasal masks were used in only 4 subjects. This is due to the difficulty of finding suitable interfaces, especially in younger infants. Although the nasopharyngeal tube may be a viable alternative interface in small patients, ${ }^{26}$ an oronasal mask was chosen whenever possible to reduce leaks. ${ }^{29}$

The statistically significant increase in the use of oronasal masks, NIV mode, and the Oxylog 3000 ventilator with a homogeneous sample can be explained by our learning curve: In the first year, we tested our protocol, so we were extremely cautious. As skills and material improved in the following years, both NIV and oronasal interface use also increased. As Baird et $\mathrm{al}^{30}$ insist, extensive training of transport teams is crucial, particularly when using NIV in infants and children.

In our study, we observed 6 failures in the referring hospital due to asynchrony and 6 failures due to lack of improvement. These results would probably be better if we had better material, especially ventilators with appropriate triggers (the minimum trigger for the Oxylog is $3 \mathrm{~L} / \mathrm{min}$, and the Crossvent does not have an NIV mode).

Subjects were sedated due to material limitations and asynchrony to improve NIV tolerance. As reported previ- 


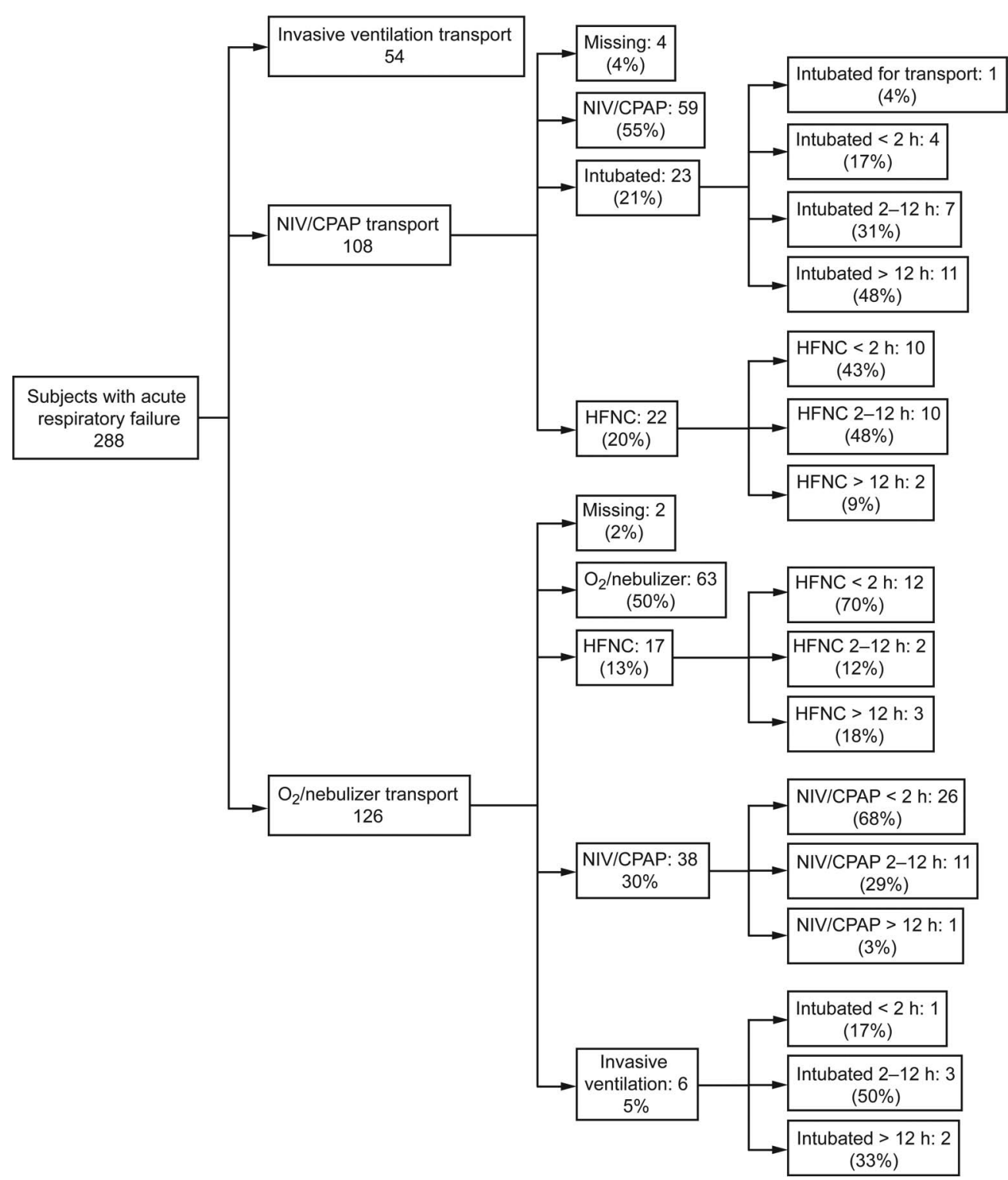

Fig. 2. Subject evolution in the tertiary care receptor hospitals. HFNC = high-flow nasal cannula, NIV = noninvasive ventilation.

ously, ${ }^{31}$ the use of sedation has been shown to be safe and feasible with NIV. In this study, we used sedation in only $26 \%$ of our subjects. This is a very low number in comparison with other NIV studies, where sedation was used in up to $50 \%$ of the subjects. ${ }^{32-34}$ The low percentage of sedation could be explained by an initial fear of decreasing the subject's level of consciousness.

Stabilization time is an important piece of data to collect. Our transport team usually needs $15-30$ min for medical decisions, which is why our protocol had strict rules: We did not apply NIV during transport to any subject with severe ARF who did not show clear improvement in severity score in this short period of time.

Also, although we know that an inspiratory positive airway pressure maximum level of $18 \mathrm{~cm} \mathrm{H}_{2} \mathrm{O}$ seems a little restrictive, we consider that limit to avoid complications during transport. Predictive factors for NIV success reported in the literature were used, such as a decrease in heart rate, breathing frequency, oxygen needs measured by $\mathrm{S}_{\mathrm{pO}_{2}} / \mathrm{F}_{\mathrm{IO}_{2}}$, or an improvement in work of breathing. $32,34,35$

No significant adverse effects were documented with NIV in our study, with only a few minor complications observed. It should be stressed that only one subject required intubation during transport. A post-transport analysis of this subject's clinical chart suggests that this subject had ongoing ARDS, which should have been detected before leaving the referring hospital because it is an important contraindication for NIV during transport in our protocol. In our study, $75 \%$ of NIV/CPAP-transported subjects avoided intubation in the tertiary hospitals where 
they were transferred, a success rate similar to the majority of NIV studies in the pediatric population of around $75 \% .7,18,32$

It is possible that our subjects did not need NIV/CPAP so early, but if we follow their evolution, this overtreatment was minimal, with only $20 \%$ of our NIV/CPAP subjects successfully switched to HFNC in the tertiary-care receptor hospitals. Findings from the randomized controlled trial of Yañez et $\mathrm{al}^{7}$ showed that $40 \%$ of the control group avoided intubation without receiving NIV.

This study has several limitations. The first is that our data come from a single transport unit with a relatively small sample size, which lacked statistical power to detect a significant decrease in intubation rate in our population, as previous studies have shown. ${ }^{10,11,14}$ Moreover, we should take into account that there were several tertiary-care receptor hospitals involved, with varying levels of NIV/CPAP expertise, so the final intubation rate depended on several factors not related to the transport itself. Second, it is possible that the increase in NIV/CPAP use may partially represent overtreatment of some subjects who hypothetically would have done well while receiving HFNC therapy, as some studies suggest. ${ }^{17,25}$ Further studies are needed to evaluate a scoring system that identifies appropriate candidates for noninvasive support. Third, we can only generalize our data to the population that have a transport system similar to ours. And finally, this study has no data for the recently introduced small pediatric total face masks. This interface has shown preliminary but promising results in critically ill adult patients failing with oronasal masks. ${ }^{36}$

\section{Conclusions}

Noninvasive respiratory support seems to be safe and feasible during pediatric ground transport in subjects with ARF. This respiratory support improved subjects' condition during transfer to the PICUs. A restrictive protocol, careful selection avoiding moderate and severe ARDS patients, and a well-trained retrieval team are essential for using NIV or CPAP during transport.

Finally, suitable material and ventilators are needed to improve adaptation to NIV/CPAP and success. Nevertheless, the data obtained seem promising, so noninvasive support in the transport setting deserves further research.

\section{ACKNOWLEDGMENTS}

We gratefully acknowledge the efforts of all nursing and medical staff of the Transport Unit of Hospital Sant Joan de Déu in this project. We also thank the Catalonian tertiary-care hospitals (Vall d'Hebron, Sant Pau, Corporació Sanitaria Parc Taulí, and Josep Trueta) who facilitated the data of our subjects' evolution.

\section{REFERENCES}

1. Ajizian SJ, Nakagawa TA. Interfacility transport of the critically ill pediatric patient. Chest 2007;132(4):1361-1367.
2. Fortenberry JD, Del Toro J, Jefferson LS, Evey L, Haase D. Management of pediatric acute hypoxemic respiratory insufficiency with bilevel positive pressure (BiPAP) nasal mask ventilation. Chest 1995; 108(4):1059-1064.

3. Padman R, Lawless ST, Kettrick RG. Noninvasive ventilation via bilevel positive airway pressure support in pediatric practice. Crit Care Med 1998;26(1):169-173.

4. Essouri S, Durand P, Chevret L, Haas V, Perot C, Clement A, et al. Physiological effects of noninvasive positive ventilation during acute moderate hypercapnic respiratory insufficiency in children. Intensive Care Med 2008;34(12):2248-2255.

5. Thill PJ, McGuire JK, Baden HP, Green TP, Checchia PA. Noninvasive positive-pressure ventilation in children with lower airway obstruction. Pediatr Crit Care Med 2004;5(4):337-342.

6. Essouri S, Nicot F, Clément A, Garabedian EN, Roger G, Lofaso F, Fauroux B. Noninvasive positive pressure ventilation in infants with upper airway obstruction: comparison of continuous and bilevel positive pressure. Intensive Care Med 2005;31(4):574-80.

7. Yañez LJ, Yunge M, Emilfork M, Lapadula M, Alcántara A, Fernández $\mathrm{C}$, et al. A prospective, randomized, controlled trial of noninvasive ventilation in pediatric acute respiratory failure. Pediatr Crit Care Med 2008;9(5):484-9.

8. Roessler MS, Schmid DS, Michels P, Schmid O, Jung K, Stöber J et al. Early out-of-hospital non-invasive ventilation is superior to standard medical treatment in patients with acute respiratory failure: a pilot study. Emerg Med J 2012;29(5):409-414.

9. Brywczynski JJ, Barrett TW, Schriger DL. Out-of-hospital continuous positive airway pressure ventilation versus usual care in acute respiratory failure: a randomized controlled trial. Ann Emerg Med 2008;52(3):242-243.

10. Williams TA, Finn J, Perkins GD, Jacobs IG. Prehospital continuous positive airway pressure for acute respiratory failure: a systematic review and meta-analysis. Prehosp Emerg Care 2013;17(2):261-273.

11. Ducros L, Logeart D, Vicaut E, Henry P, Plaisance P, Collet JP, et al. CPAP for acute cardiogenic pulmonary oedema from out-ofhospital to cardiac intensive care unit: a randomised multicentre study. Intensive Care Med 2011;37(9):1501-1509.

12. Ram FSF, Picot J, Lightowler J, Wedzicha JA. Non-invasive positive pressure ventilation for treatment of respiratory failure due to exacerbations of chronic obstructive pulmonary disease. Cochrane Database Syst Rev 2004;(1):CD004104.

13. Schmidbauer W, Ahlers O, Spies C, Dreyer A, Mager G, Kerner T. Early prehospital use of non-invasive ventilation improves acute respiratory failure in acute exacerbation of chronic obstructive pulmonary disease. Emerg Med J 2011;28(7):626-627.

14. Murray PG, Stewart MJ. Use of nasal continuous positive airway pressure during retrieval of neonates with acute respiratory distress. Pediatrics 2008;121(4):e754-e758.

15. Chabernaud JL, Jourdain G, Durand S. Non invasive ventilation for severe infant bronchiolitis. Arch Pediatr 2009;16(6):726-728.

16. Baird JS, Spiegelman JB, Prianti R, Frudak S, Schleien CL. Noninvasive ventilation during pediatric interhospital ground transport. Prehosp Emerg Care 2009;13(2):198-202.

17. Schlapbach LJ, Schaefer J, Brady AM, Mayfield S, Schibler A. High-flow nasal cannula (HFNC) support in interhospital transport of critically ill children. Intensive Care Med 2014;40(4):592-599.

18. Essouri S, Chevret L, Durand P, Haas V, Fauroux B, Devictor D. Noninvasive positive pressure ventilation: five years of experience in a pediatric intensive care unit. Pediatr Crit Care Med 2006;7(4):329334.

19. Teague WG. Noninvasive ventilation in the pediatric intensive care unit for children with acute respiratory failure. Pediatr Pulmonol 2003;35(6):418-426. 


\section{Noninvasive Support During Pediatric Transport}

20. Balaguer M, Alejandre C, Vila D, Esteban E, Carrasco JL, Cambra FJ, Jordan I. Bronchiolitis Score of Sant Joan de Déu: BROSJOD Score, Validation and usefulness. Pediatr Pulmonol 2016. DOI 10.1002/ppul.23546

21. Wood DW, Downes JJ, Lecks HI. A clinical scoring system for the diagnosis of respiratory failure. Preliminary report on childhood status asthmaticus. Am J Dis Child 1972;123(3):227-228.

22. Caritg J, Ortega J, Artigas S, Pons M, Mainou C, Camarasa F. Bronquiolitis: aspectos novedosos actuales: pauta de actuación. Arch Pediatr (Barc) 1999;50(2):104-111.

23. Essouri S, Durand P, Chevret L, Balu L, Devictor D, Fauroux B, Tissières $\mathrm{P}$. Optimal level of nasal continuous positive airway pressure in severe viral bronchiolitis. Intensive Care Med 2011;37(12): 2002-2007.

24. Milési C, Matecki S, Jaber S, Mura T, Jacquot A, Pidoux O, et al. 6 $\mathrm{cm} \mathrm{H}_{2} \mathrm{O}$ continuous positive airway pressure versus conventional oxygen therapy in severe viral bronchiolitis: a randomized trial. Pediatr Pulmonol 2013;48(1):45-51.

25. Tent Brink F, Duke T, Evans J. High-flow nasal prong oxygen therapy or nasopharyngeal continuous positive airway pressure for children with moderate-to-severe respiratory distress?. Pediatr Crit Care Med 2013;14(7):e326-e331.

26. Velasco Arnaiz E, Cambra Lasaosa FJ, Hernández Platero L, Millán García Del Real N, Pons-Òdena M. Is a nasopharyngeal tube effective as interface to provide bi-level noninvasive ventilation? Respir Care 2014;59(4):510-517.

27. Mayordomo-Colunga J, Medina A, Rey C, Los Arcos M, Concha A, Menéndez S. [Success and failure predictors of non-invasive ventilation in acute bronchiolitis]. An Pediatr (Barc) 2009;70(1):34-39.

28. Toledo Del Castillo B, Gonzalez Ruiz de Leon E, Rivas Garcia A, Vazquez Lopez P Miguez Navarro M Maranon Pardillo R. [Association between moderate-severe bronchiolitis and syndrome of inap- propriate antidiuretic hormone secretion in emergency departments]. An Pediatr (Barc) 2016;84(1):24-29.

29. Girault C, Briel A, Benichou J, Hellot MF, Dachraoui F, Tamion F, Bonmarchand $\mathrm{G}$. Interface strategy during noninvasive positive pressure ventilation for hypercapnic acute respiratory failure. Crit Care Med 2009;37(1):124-131.

30. Baird JS, Ravindranath TM. Out-of-hospital noninvasive ventilation: epidemiology, technology and equipment. Pediatr Rep 2012;4(2): e17.

31. Hilbert G, Clouzeau B, Nam Bui H, Vargas F. Sedation during non-invasive ventilation. Minerva Anestesiol 2012;78(7):842-846.

32. Mayordomo-Colunga J, Medina A, Rey C, Díaz J, Concha A, Los Arcos M, Menéndez S. Predictive factors of non invasive ventilation failure in critically ill children: a prospective epidemiological study. Intensive Care Med 2009;35(3):527-536.

33. Mayordomo-Colunga J, Medina A, Rey C, Concha A, Menéndez S, Arcos M, Vivanco-Allende A. Non-invasive ventilation in pediatric status asthmaticus: a prospective observational study. Pediatr Pulmonol 2011;46(10):949-955

34. Bernet V, Hug MI, Frey B. Predictive factors for the success of noninvasive mask ventilation in infants and children with acute respiratory failure. Pediatr Crit Care Med 2005;6(6):660-664.

35. Mayordomo-Colunga J, Pons M, López Y, José Solana M, Rey C, Martínez-Camblor $\mathrm{P}$, et al. Predicting non-invasive ventilation failure in children from the $\mathrm{SpO} / \mathrm{FiO}(\mathrm{SF})$ ratio. Intensive Care Med 2013;39(6): 1095-1103

36. Lemyze M, Mallat J, Nigeon O, Barrailler S, Pepy F, Gasan G, et al. Rescue therapy by switching to total face mask after failure of face mask-delivered noninvasive ventilation in do-not-intubate patients in acute respiratory failure. Crit Care Med 2013;41(2): 481-488. 